ARTIGO

\title{
O modelo liberal tecnoburocrático e as recentes reformas educacionais brasileiras: limites da tese reformista na perspectiva marxista
}

\author{
Osterne Nonato Maia Filho' \\ Maria das Dores Mendes Segundo' (D) \\ Josefa Jackline Rabelo" (D) \\ Maria Susana Jimenez"

RESUMO

No presente ensaio, buscamos analisar três teses reformistas implantadas nos marcos do liberalismo tecnoburocrático assumido pelo capitalismo em crise no Brasil. A primeira tese explicita o modus operandi das reformas educacionais colocadas em prática a partir de 1990, especialmente na América Latina, que se configuraram, inicialmente, como estratégias ditas inovadoras de financiamento e gestão para depois se materializarem como reformas curriculares. A segunda tese analisa os fundamentos filosóficos mais amplos que amparam o reformismo educacional brasileiro. E, como consequência, elucidamos a terceira tese: com o propósito de combater as resistências sociais, são implementadas medidas e/ou projetos pontuais, articulados ao modelo de gestão tecnoburocrático e liberal. No contraponto a essas teses, desvelamos, à luz da crítica marxista, seus limites e a inconsistência de seus fundamentos, apresentando, como ilustração, experiências reformistas brasileiras no campo educacional.

PALAVRAS-CHAVE

neoliberalismo; reformas educacionais; modelo tecnoburocrático. 
THE TECHNO-BUREAUCRATIC LIBERAL MANAGEMENT MODEL AND THE RECENT BRAZILIAN EDUCATIONAL REFORMS: LIMITS OF THE REFORMIST THESIS IN THE MARXIST PERSPECTIVE

\begin{abstract}
In the present essay, we seek to analyze three reformist theses implanted within the framework of techno-bureaucratic liberalism assumed by capitalism in crisis in Brazil. The first thesis explains the modus operandi of the educational reforms implemented since 1990, especially in Latin America, which were, initially, defined as innovative financing and management strategies and later materialized as curricular reforms. The second thesis analyzes the broader philosophical foundations that support Brazilian educational reformism. And, as a consequence, the third thesis is elucidated: with the purpose of fighting social resistance, specific measures and/or projects are implemented, articulated to the techno-bureaucratic and liberal management model.In the counterpoint to these theses, we reveal, in the light of Marxist criticism, the limits and the inconsistency of its foundations, presenting, as an illustration, Brazilian reformist experiences in the educational field.
\end{abstract}

KEYWORDS

neoliberalism; educational reforms; techno-bureaucratic management model.

\title{
EL MODELO LIBERAL TECNO-BUROCRÁTICO Y LOS RECIENTES REFORMAS EDUCACIONALES BRASILEÑAS: LÍMITES DE LA TESE REFORMISTA EN LA PERSPECTIVA MARXISTA
}

\section{RESUMEN}

En el presente ensayo, buscamos analizar tres tesis reformistas implantadas en los marcos del liberalismo tecno-burocrático asumido por el capitalismo en crisis en Brasil. La primera tesis explicita el modus operandi de las reformas educativas implantadas, a partir de 1990, especialmente en América Latina, que se configuraron, inicialmente, como estrategias dichas innovadoras de financiamiento y gestión para luego materializarse como reformas curriculares. La segunda tesis analiza los fundamentos filosóficos más amplios que amparan el reformismo educativo brasileño. Entonces, como consecuencia, se elucida la tercera tesis: con el propósito de combatir las resistencias sociales, se implementan medidas y/o proyectos puntuales, articulados al modelo de gestión tecno-burocrático y liberal. En el contrapunto a esas tesis, desvelamos, a la luz de la crítica marxista, sus límites y la inconsistencia de sus fundamentos, presentando, como ilustración, experiencias reformistas brasileñas en el campo educativo.

PALABRAS CLAVE

neoliberalismo; reformas educativas; modelo tecno-burocrático. 


\section{INTRODUÇÃO}

O presente ensaio teórico debate, primeiramente, importantes limites das concepções de reformas presentes no pensamento liberal, ilustrado pelas considerações de Bobbio (2000), e sua aplicação no campo educacional brasileiro recente, como analisado por Ferreira e Fonseca (2011) e Aguiar (2003) acerca da temática. Em um segundo movimento do texto, expomos a crítica ao projeto de cunho reformista, fundamentada agora na leitura em Marx (1989). Esse autor afirma que uma revolução econômica e política no capitalismo dependem necessariamente de uma ampla ruptura econômica e social, visto que o capitalismo só se constituiu dessa forma como um sistema específico de produção de riqueza porque se estrutura sobre certas relações sociais de produção que precisam ser superadas, tais como: a apropriação privada dos produtos e meios de produção; a lógica do trabalho abstrato configurada no tempo de trabalho socialmente necessário para a produção de um bem; relações de trocas baseadas no funcionamento do mercado; relações alienadas de trabalho; sociabilidade baseada na produção e expropriação da mais-valia que se realiza na troca social, e assim por diante. Em consonância com a tese de Mészáros (2005), para quem vivenciamos um contexto de crise estrutural do capital, buscamos destacar a função do Estado moderno/burguês e suas estratégias para a manutenção do processo de acumulação do capital e exploração do trabalho humano.

Do ponto de vista econômico e político, o reformismo a que nos referimos corresponde a um tipo de mudança, mediante a implantação de políticas econômicas e sociais diversas, que não afeta o objeto, a estrutura básica e as relações sociais do sistema capitalista.

Em contraposição ao reformismo, compreendemos que o processo revolucionário implica uma ruptura radical no campo econômico, cultural e político de tal ordem que altera a própria essência do ser ou da formação social, produzindo sua transformação em outro objeto ou outra formação com propriedades novas, permitindo a emancipação humana para além da lógica mercantilista e liberal burguesa.

Muitos reformistas argumentam que as políticas sociais e os ajustes que propõem representam a revolução possível, ou o caminho necessário para preparar as futuras condições revolucionárias. Mas tal concepção linear, e muitas vezes mecânica, parece não contar com o fato de que o movimento da realidade não é necessariamente progressivo. Além do mais, em vez de ser um caminho, o reformismo pode ser também a via mais curta para o adiantamento ou suspensão dessas condições revolucionárias, pois, quando as questões estruturais não são enfrentadas, as energias da sociedade podem ser redirecionadas para mudanças que só aparentemente solucionam os problemas e as crises enfrentadas.

Se a própria concepção de reforma é por si uma visão limitada de transformação social, pretendemos, mediante revisão da literatura acerca da temática, demonstrar a insuficiência dos próprios fundamentos econômicos e políticos, procedimentos técnicos e estratégias operacionais do reformismo. Com o fito de cumprir nossos objetivos, a discussão foi dividida em quatro seções: os fundamentos do reformismo; o legalismo e o gradualismo no financiamento e a gestão da reforma; o focalismo dos procedimentos reformistas; o contraponto marxista e a perspectiva revolucionária em educação. 


\section{OS FUNDAMENTOS DO REFORMISMO: LEGALIDADE, GRADUALIDADE, PARCIALIDADE E FOCALISMO}

Aguiar (2003) trabalha com dois conceitos de reforma que, segundo sua perspectiva, são complementares. Com base na concepção liberal de Bobbio (2000), o autor destaca que a reforma é um processo predominantemente político de mudança legal, gradual e parcial da realidade social. Noutra frente, tomando considerando a definição do Banco Interamericano de Desenvolvimento (BID) (1997), a reforma é concebida tendo como foco predominante seu viés econômico: ela seria um conjunto de instrumentos eficazes de planejamento político-econômico para produzir crescimento econômico, prosperidade, equidade social e redução de pobreza.

Desse ponto de vista econômico defendido pelo BID, esse conjunto de instrumentos redunda em um bloco de ações coordenadas visando à reorganização e à reestruturação produtiva por meio de gastos e investimentos de cunho público, privado ou público-privado, com o objetivo de promover ajustes entre a demanda e a oferta de bens econômicos, o restabelecimento da eficácia do sistema produtivo, a distribuição de renda e o crescimento humano. A reforma, nesses termos, revisa prioridades dos gastos e investimentos governamentais, estreitando a articulação entre sociedade civil e a iniciativa privada.

Não se trataria, no entanto, de visões complementares, mas de focos diferentes. A intenção era buscar um conceito amplo que comportasse as reformas em geral, incluindo as reformas econômicas, para demonstrar que as reformas liberais implantadas na América Latina seguiam uma mesma lógica e fundamentação. A leitura liberal de Bobbio (2000) é menos eficientista que aquela apresentada pelo BID, pois para ele as concepções reformistas são tributárias de uma necessária visão progressista de mudança da sociedade, com a intenção de controlar e determinar o movimento espontâneo, autônomo e natural das mudanças sociais para que não redundem em crise, estagnação e fragmentação do tecido social. Por sua vez, é preciso esclarecer que Bobbio não se enquadra na perspectiva do neoliberalismo radical de Friedman e Hayek (Bueno, 2012), mas em um meio termo entre perspectiva liberal burguesa e o social-liberalismo, tão a gosto do Governo Fernando Henrique Cardoso (FHC) (Bresser-Pereira, 1994).

Dentro dessa lógica mais ampla da mudança social, as reformas educacionais parecem ser movidas, em sua especificidade, pelas demandas sociais de acesso ao saber já constituído ou pelo avanço da ciência. A partir do século XX, de uma forma truncada e extremamente desigual, a educação tornou-se cada vez mais universal, laica e gratuita, passando a constituir-se, ao menos no plano retórico e legal, como um direito inalienável do cidadão e dever incontornável do Estado. Essa mudança corresponde ao desenvolvimento das forças produtivas e da luta de classes, o que resultou na atual configuração dos Estados nacionais. A educação em massa, mesmo de caráter reprodutivista e assistencial, corresponde, hoje, a uma das funções vitais do Estado, que, assim, precisa garantir a todo cidadão o acesso ao saber minimamente necessário à interação social, segundo as exigências do mercado, em nome dos valores que formam a identidade nacional, em contraponto ao dever de cada sujeito de defender o bem comum, que, no Estado burguês, 
corresponde a defender os bens dos que os possuem, ou seja, dos detentores da propriedade privada.

Nesse sentido, o tempo das reformas educacionais parece ser diferente daquele das reformas econômicas, cujos planos, determinações e decretos podem produzir mudanças quase que imediatas sobre a realidade, considerando que, no caso das primeiras, seus efeitos só podem aparecer, muitas vezes, depois de transcorridas gerações. O tempo pedagógico em que se produzem mudanças na gestão e na estrutura técnico-pedagógica e curricular não obedece, portanto, à diacronia que move o tempo das interdeterminações econômicas, políticas e culturais que agem sobre a reforma. Esse movimento acaba produzindo, muitas vezes, um campo de tensão entre o tempo político do núcleo técnico-burocrático governamental encarregado de fazer a reforma e o ritmo específico do cotidiano da escola e das salas de aula.

Todavia, se as reformas educacionais não podem ser vistas dissociadas do contexto social mais amplo, por que apenas a elas caberia o "privilégio" de um tempo geracional? Ora, o processo de mudança da sociedade e as reformas que eventualmente possam acompanhar essas transformações apenas produzem seus efeitos mais significativos em longo prazo, embora medidas focais possam "acelerar" esse tempo e produzir efeitos mais imediatos.

Ainda segundo essa visão, reforça-se a concepção de que, para que a reforma se constitua como uma resposta adequada às mudanças, é fundamental que ela tenha sustentabilidade, consoante ao que os positivistas explicitaram como a ordem no progresso, em que as mudanças devem ser ordenadas segundo a intenção consciente da humanidade. A ordem, a estabilidade, são precondições para o progresso, para "avançar nas mudanças" na forma determinada pela intencionalidade humana, mas que já existe também nas leis e na causalidade da natureza (Comte, 1976). Portanto, para garantir a mudança é preciso dar-lhe sustentabilidade por meio de procedimentos políticos, legais e estratégias técnicas de operacionalização, como se verifica em diversos processos reformistas no âmbito da sociedade capitalista.

\section{SUSTENTABILIDADE DAS REFORMAS: LEGALISMO E GRADUALISMO NAS POLÍTICAS DE FINANCIAMENTO E GESTÃO}

O primeiro elemento necessário para garantir a sustentabilidade da reforma educacional é sua institucionalização em procedimentos administrativos de gestão e financiamento (modelo concreto, responsáveis, objetivos, cronograma, recursos garantidos, controle, entre outros) de operacionalização do sistema de ensino. Trata-se de garantir a infraestrutura da reforma. Um segundo ponto fundamental é a consistência da política educacional, no que diz respeito às suas diretrizes maiores, com a organização interna do poder público e suas relações externas com a sociedade, além da factibilidade dos objetivos a serem alcançados. Se a organização interna pode ser garantida pelo modelo de gestão, a homogeneidade dos diferentes agentes que compõem o atual sistema educacional brasileiro (escolas públicas federais, estaduais e municipais, escolas privadas, escolas confessionais, entre outras) só pode ser garantida mediante certo pacto de abertura e concessão do Estado, segundo uma 
legislação específica, à atuação do mercado na educação. A própria grandiosidade do sistema público, mas principalmente o suporte estatal que com ele se confunde, garante certa estabilidade ao sistema, pois seria inadmissível presumir a falência do Estado.

No entanto, o elemento mais importante, mesmo do ponto de vista reformista, para a sustentabilidade da reforma educacional é a consolidação da reforma social mais ampla na qual esta se insere, de sua compatibilização com o tempo político, econômico e cultural do movimento mais amplo da sociedade.

A necessidade de sustentabilidade e estabilidade parece contradizer a própria noção de reforma de Bobbio (2000) enquanto uma mudança legal, gradual e parcial, visto que sustentabilidade se coaduna melhor com uma ação simultânea, integrada e totalizadora do dado da realidade. Mas essa contradição é apenas superficial.

Nesse sentido, ao legal não se contrapõe apenas o ilegal, mas também o legítimo. A legalidade funda o Estado de direito do ponto de vista formal, pois se constitui no ordenamento jurídico que resulta do pacto social no Estado moderno. A formulação das leis no patamar do Legislativo e sua operacionalização pelo Executivo, sob a guarda do Judiciário, já se constitui, em si, em um sistema legal e formal de criação e alteração das leis. No entanto, o verdadeiro campo de elaboração das leis está na sociedade que as cria e as cumpre, o campo da legitimidade, pois, se o legal não se legitima, ele se transforma em "letra morta" ou motivo de batalha entre o poder de quem executa o legal, poder de direito, e o poder da sociedade que o aceita ou não como legítimo, o poder de fato. Nesse escopo, o ideal é que as leis sejam reconhecidas pelo grupo social e, assim, internalizadas, de forma que o poder de direito corresponda ao poder de fato.

$\mathrm{Na}$ sociedade contemporânea, a classe dominante, representada no Estado, se antecipa ao movimento social na formulação e implementação das leis que, em nome do bem comum, atendem, na verdade, aos seus interesses no processo de acumulação e ampliação do capital. No Brasil, país de longa tradição autoritária, é comum o Estado elaborar e promulgar as leis para só depois tentar legitimá-las, o que demonstra que seu poder, embora legal, não emana - nem poderia sob as atuais condições de funcionamento da sociedade brasileira - verdadeiramente do corpo social. Porém, a necessidade da legitimação demonstra que o poder legal não é ainda absoluto, o que se torna um espaço de abertura fundamental para que os movimentos sociais possam, por meio de suas lutas, apesar dos seus limites, influenciar o pacto social. Embora o movimento reformista brasileiro tenha tido início após a queda do regime militar, seu status civil não é sinônimo, por si, de legitimidade.

A reforma educacional desencadeada pelo Governo FHC no período de 1995-2000 constituiu o fim de uma longa transição reformista em educação iniciada com a Constituição de 1988, estando, ainda, inserida no contexto de outras reformas do Estado desencadeadas naquele período. O capítulo da educação dessa Constituição estabeleceu vários mecanismos de universalização e publicização da educação que se contrapunham ao modelo técnico-liberal de reforma de Thatcher (19791990), na Inglaterra, que inspirou o ciclo internacional de reformas na educação.

Enquanto o modelo inglês se baseava na racionalidade econômica e empresarial aplicada à escola, na busca da eficiência ao menor custo financeiro, no incentivo 
à competitividade entre as instituições de ensino, na descentralização da gestão para as escolas e na centralização dos controles pelo Estado nacional, a Constituição brasileira de 1988 reafirmou princípios em direção contrária, tais como a gratuidade do ensino público, a vinculação de recursos mínimos a serem aplicados em educação e o concurso público; atualizou outros, como a obrigatoriedade de o Estado fornecer o ensino fundamental, a autonomia universitária, o recenseamento escolar; e introduziu princípios novos, como a gestão democrática na escola, a valorização do magistério e os parâmetros para um plano nacional de educação.

Por essa razão, a maior parte das reformas liberais propostas a partir do Governo FHC se constituiu como leis e emendas à Constituição Federal de 1988 , que redundaram na retirada de muitas das conquistas ali consagradas. $\mathrm{Na}$ área educacional, especificamente, o movimento de transição reformista pode ser resumido como a passagem do modelo estatal varguista (1930-1990) para o modelo de mercado implantado pelo Governo FHC (1995-2002), mais próximo do espírito tecnoliberal do Governo Thatcher. Como a reforma do ensino médio foi desencadeada oficialmente em 1998, seu espírito não poderia ser outro, pelo menos do ponto de vista legal, senão aquele do modelo eficientista de gestão cujo viés tecno-burocrático-liberal será predominante.

Já a noção de reforma como movimento gradual no tempo contrapõe-se à simultaneidade ou ainda à mudança brusca, como, a rigor, aconteceria em um processo revolucionário. Para Lewin (1999), epistemologicamente, a noção de gradualidade é uma das mais importantes conquistas da ciência moderna. $\mathrm{O}$ pensamento dialético, desde a Antiguidade, já havia acentuado que, para se compreender as mudanças, era fundamental acompanhar as várias modificações e mediações que se foram acumulando pouco a pouco até que essa realidade se caracterizasse efetivamente como mudança.

O conceito de gradualidade apresenta-se no movimento reformista em educação e se justifica pela dificuldade de tornar sincrônico o ritmo pedagógico da reforma com o ritmo político, econômico e cultural da sociedade. Além disso, é preciso conciliar os interesses e as pressões de curto prazo dos vários agentes envolvidos no processo e os objetivos de longo prazo daí advindos. É nesse sentido que Aguiar (2003) defende que há uma sequência na implantação das reformas educacionais que praticamente se repetiu na América Latina, especialmente no Brasil, no Chile e na Argentina.

Dessa forma, as reformas se iniciaram com o estabelecimento de um novo modelo concreto e factível de gestão e financiamento do ensino compatíveis com a lógica liberal, cujos elementos centrais foram: descentralização e responsabilização dos entes federativos; sistemas nacionais de avaliação e de controle centralizados; e políticas parcialistas de focalização e participação da comunidade. Implantada a reforma na concretude do financiamento e da gestão, é então dado o segundo passo para a elaboração de uma reforma curricular e de uma política de formação dos profissionais da educação para que estes se tornem também agentes da reforma.

Há, obviamente, uma lógica muita clara nessa sequência, pois, no contraponto do movimento de descentralização de poder e de transferência, há um movimento inverso de centralização e de controle representado pelo desenvolvimento de um 
sistema de avaliação. $\mathrm{O}$ governo torna-se, na prática, apenas um agente regulador. É por essa razão que a reforma curricular e uma nova formação docente com ela compatível só devem aparecer em um segundo momento, quando o modelo de gestão já instalado possa, imediatamente, detectar os problemas e propor as soluções. Esse encadeamento pode ser perfeitamente observado na reforma educacional implementada pelo Governo FHC, assim como, igualmente, a exemplo da reforma do ensino médio proposta nos anos de 1990.

Havia, naquela ocasião, uma clara intenção de fazer da estratégia da gradualidade um caminho para a legitimidade. Desse modo, o novo modelo de gestão legalmente estabelecido passou a produzir um patamar diferente de responsabilização dos entes federados e da escola e a aceitação, no tempo, dessas novas atribuições, mesmo que às vezes sem os recursos e o know-how necessários ao desenvolvimento das novas atividades. Por sua vez, a participação no diagnóstico dos problemas visava produzir a aceitação e a legitimação do sistema de avaliação e, obviamente, das medidas curriculares e pedagógicas para sua correção. Ressaltamos que a legalização e a legitimação do novo processo de gestão abriram espaço para um modelo bem mais flexível de administração dos sistemas educacionais, no qual a escola, os vários entes federados e, particularmente, a iniciativa privada e o mercado passaram a interagir conforme os critérios e os controles estabelecidos pelo governo central. Por essa lógica, o governo central deixa de ser o responsável direto pela execução das ações do sistema educacional para agir, ao final do processo, apenas como uma agência de regulação das atividades educacionais.

A tese implícita na estratégia de legitimação por meio de medidas graduais é de que as mudanças produzidas no âmbito da sociedade tecnológica são mais rápidas e permanentes, logo somente sistemas educacionais flexíveis e dinâmicos seriam capazes de acompanhar tais mudanças. Aliás, caberia ao sistema adequar-se à nova realidade dos processos pedagógicos cada vez mais sintonizados com o paradigma das competências e do ideário da pedagogia do aprender a aprender, recomendados, igualmente, nos termos dos documentos resultantes das conferências e fóruns de "Educação para Todos", sob a tutela da Organização das Nações Unidas para a Educação, a Ciência e a Cultura (UNESCO) e do Banco Mundial (Maia Filho e Jimenez, 2004).

$\mathrm{O}$ fato de que as reformas obedecem a uma lógica e racionalidade tecnoinstrumental tem dupla explicação. Em primeiro lugar, essa racionalidade corresponde a uma ampla tecnologia de controle e regulação social desenvolvida internacionalmente com base na experiência de inúmeros países, sendo então adaptadas à realidade reformista de cada nação. Aplica-se, com efeito, uma tecnologia de regulação social, uma espécie de modelo padrão de detecção de problemas e desequilíbrios, de mobilização dos aí envolvidos e de todo um conjunto de técnicas apropriadas para aproveitar a "janela de oportunidades" em que uma conjunção de fatores favorece a resolução do desequilíbrio detectado. Trata-se, na verdade, de mudar para manter as coisas como estão, pois nesse processo jamais o sistema capitalista é posto em questionamento, arguindo-se apenas o que entendem serem suas disfunções.

Em segundo lugar, desde a conferência de Jomtien, na Tailândia, em 1990, cujo lema "Educação de qualidade para todos" consagrou-se mundialmente, o uso 
dessas tecnologias vem sendo crescentemente associado às reformas educacionais na medida em que elas passaram a ser financiadas ou cofinanciadas por agências multilaterais de crédito, como o Banco Mundial e o BID, tributários dessas tecnologias. Embora não tenha sido explicitado que o objetivo da conferência era legitimar a entrada desses organismos no financiamento das demandas sociais dos países ditos em desenvolvimento, cada vez mais acossados pelo endividamento interno e externo, os empréstimos das agências multilaterais para esses mercados aumentaram substancialmente após a referida conferência (Maia Filho e Jimenez, 2004).

\section{O PARCIALISMO E O FOCALISMO COMO ESTRATÉGIAS DA REFORMA}

Além da legalidade e da gradualidade, o terceiro fundamento do conceito de reforma, a parcialidade, também se aplicou, claramente, à realidade das reformas educacionais brasileiras iniciadas nos anos de 1990. Diferentemente da noção de gradualidade associada à dimensão do tempo, o conceito de parcialidade corresponde à opção de ocupar o espaço possível, visto que o espaço total, o todo, nessa perspectiva, seria impossível de ser ocupado e controlado. A dimensão da parcialidade é a que melhor deslinda os propósitos da reforma e a quem ela se dirige e interessa. Para tanto, basta visualizar quem será atingido pelas medidas parciais da reforma: as escolas e os estudantes. Ela é também a dimensão mais claramente associada às outras duas dimensões, da legalidade e da gradualidade.

A parcialidade manifesta-se como legalidade na medida em que o governo central assume claramente, e transforma em lei, políticas de desresponsabilização e de descentralização, comprometendo o controle e a qualidade da totalidade do sistema. O poder central passa a delegar aos entes federados, às escolas, à comunidade e à iniciativa privada a responsabilidade pelo funcionamento e manutenção do sistema, cabendo a ele a regulação das relações entre as várias partes envolvidas. Essa política, aliás, era o centro do modelo de gestão da reforma do ensino médio, assim como das reformas educacionais brasileiras recentes.

Esse modelo de gestão deixa de ser apenas um modelo legal e passa a ganhar legitimidade com as políticas de focalização representadas pela introdução da cultura de projetos. Os problemas não são tratados de forma sistêmica e levando em conta a totalidade dos agentes envolvidos em sua dinâmica própria, mas são considerados pela demanda específica de cada unidade envolvida que desenvolve um projeto para solucionar sua singularidade. Como a comunidade, em alguma dimensão, envolve-se na deteç̧ão do problema e propõe soluções, ela acaba por legitimar o modelo de gestão legalmente estabelecido. A propósito, quando se considera a cultura de projetos, a reforma do ensino médio, iniciada nos anos de 1990, constituiu-se ela própria em um conjunto de projetos submetidos ao Ministério da Educação (MEC) e ao BID. Em outras palavras, ela é a parcialidade da parcialidade. Sua suposta vantagem para o Estado central é também financeira: como os recursos são sempre escassos, todos concorrem a um fundo limitado com o seu respectivo projeto, o qual será sempre insuficiente para atender à demanda dos entes federados.

Examinando criticamente essa perspectiva de monitoramento sobre a educação dos países pobres e periféricos, Fonseca (1998) defende que o Banco 
Mundial não só passa a financiar a educação, mas a exercer um papel cada vez mais político. Nessa direção, Mendes Segundo (2005, p. 52) avalia que o Banco, na justificativa de sua atuação nas últimas décadas do século $\mathrm{XX}$, promete ajudar essas nações "na estruturação econômica, no intuito de conduzi-las a um novo padrão de desenvolvimento neoliberal". Conforme esse banco, continua a autora, "a maior parte das dificuldades desses países advém da rigidez da sua economia" e, nessa direção, impõe "reformas profundas nas políticas e nas suas instituições, tais como: abertura ao comércio exterior; privatização da economia; equilíbrio orçamentário; liberação financeira; redução dos gastos públicos e regulamentação dos mercados domésticos", com o propósito de eliminar os instrumentos de intervenção social do Estado (Mendes Segundo, 2005, p. 52). É nesse escopo que entra a política de projetos como aquela financiada pelo BID no governo brasileiro nos anos de 1990.

É claro que, naquele contexto, a reforma do ensino médio não era um projeto isolado, mas inseria-se em um projeto maior de mudança de todo o sistema educacional brasileiro decorrente do capital em crise e encampado por organismos internacionais, sob a ótica de ajuste econômico e fiscal, no chamado neoliberalismo.

Nesse sentido, é fundamental ter em mente que a opção política pelo reformismo que caracterizou marcadamente o Governo FHC incorporou a lógica segundo a qual as reformas são uma estratégia adequada para o enfrentamento dos conflitos sociais e, mais que isso, elas seriam fundamentais para administrar as eventuais crises do capital. Não se trata, porém, de uma política restrita ao Governo FHC, uma vez que teve continuidade, sob diferentes matizes, nos governos subsequentes, de Lula e Dilma, como, certamente, na retomada conservadora do Governo Temer.

No âmbito da reforma educacional, as recomendações relacionadas à eficiência interna ganharam dimensão no alcance de resultados, especialmente para o ensino básico e profissionalizante. Para tal, foram orientadas medidas tais como treinamento de docentes; revisão de métodos pedagógicos e novos recursos materiais que foram destacados como necessários para a reversão desse quadro; estratégias ditas inovadoras de ensino aligeirado ou a distância foram também estimuladas. Apesar de promover e descentralizar os sistemas, a exemplo da municipalização do ensino fundamental, o governo federal permaneceu presente mediante a centralização dos mecanismos de controle, ora pela avaliação, ora por medidas como promoção automática e outras inovações pedagógicas de inspiração economicista.

Desse modo, fica clara a opção legal pela parcialidade no reformismo educacional brasileiro, verificada em duas importantes medidas tomadas pelo Governo FHC. A primeira medida diz respeito à atenção especial que esse governo passou a dar à proclamada prioridade ao ensino fundamental, em óbvio detrimento aos outros patamares de ensino; a segunda medida, a ela interligada, foi o restabelecimento da separação entre o ensino médio e a educação profissional.

Partindo de uma leitura muita própria da Lei de Diretrizes e Bases da Educação (LDB) e aceitando com bastante facilidade o argumento das agências multilaterais de crédito de que esta prioridade era a mais sábia no quadro das contas públicas do país à época, o governo central passou a desresponsabilizar-se progressiva 
e gradualmente do ensino superior e da educação profissional, considerados caros e menos prioritários, deixando o espaço largamente aberto para a iniciativa privada. Segundo Mancebo (2015), mais de 70\% do ensino superior do país já se encontra nas mãos da iniciativa privada. Essas medidas acabaram tornando-se leis no corpo do processo de reformas, mas sua legitimação social parece não ter encontrado suficiente respaldo na população.

A parcialidade, por sua vez, manifestou-se como gradualidade quando o centro das mudanças propostas pelas reformas passou a tomar a forma de inovações pontuais, novidades fenomênicas que não tocam na essência do sistema educacional ou em suas relações com o sistema social mais amplo. Tratava-se da "reforma possível", sempre oferecendo o mínimo de recursos e do padrão de qualidade, em que a melhoria do sistema (do acesso, da eficiência, da qualidade) não é entendida como um projeto de médio e longo prazo, como uma política de Estado, mas contenta-se com políticas compensatórias e focais de curto prazo, que não trabalham verdadeiramente as causas fundamentais dos problemas do sistema educacional.

No Ceará, por exemplo, entre os anos 2000 e 2003, o problema da distorção idade-série no ensino fundamental e médio foi atacado por uma política pública denominada "Tempo de Avançar" (Maia Filho, 2004). Tratou-se de uma associação entre o governo do Estado e a Rede Globo de televisão. Com base nesse programa, o aluno em distorção poderia fazer as três séries do ensino médio, por exemplo, em um único ano e, caso fosse aprovado no exame final, receberia a certificação correspondente a esse patamar de ensino.

O primeiro questionamento acerca de tal política diz respeito aos fundamentos de tão revolucionário método de aprendizagem adotado pelo programa, que consegue fazer com que o aluno aprenda em um ano o que ele não conseguiu aprender nos cinco ou seis anos em que frequentou o ensino médio. A segunda questão concerne, sem dúvida, à própria qualidade do exame final de certificação. Ora, se a solução era tão simples, por que os princípios embutidos no programa não são aplicados à realidade da sala de aula da escola pública?

Outro exemplo da parcialidade enquanto gradualidade está representado na política da reforma cearense do ensino médio, que toma "a escola como ponto de partida". Em tese, a escola iria gradualmente assumindo sua autonomia, a responsabilidade pelo seu próprio destino. Tratava-se de uma política para a autonomia escolar, mas que colocava uma série de dilemas para o sistema de ensino. Assim, se a escola é apenas uma parte do sistema, quem atentaria para a relação entre as escolas? Quem planejaria os objetivos e fins do sistema como um todo? Quem cuidaria para que o sistema não se transformasse em um conjunto fragmentado e desarticulado de ações? Além disto, impedimentos legais e até da realidade social mais ampla necessariamente limitam a autonomia da escola. Exceto, é claro, se o contexto e a perspectiva forem outros: a escola não pode resolver seus problemas somente considerando a sua própria realidade, como, tampouco, pode ser refém absoluto de determinações exteriores a sua realidade. A escola é parte de um todo: não há transformação possível senão pela consideração dessa totalidade. 


\section{O VIÉS REFORMISTA NA EDUCAÇÃO NO CONTEXTO DA CRÍTICA MARXISTA}

Partimos da compreensão de que a educação tem se colocado, muitas vezes, como redentora das mazelas sociais de toda ordem, tese esta bastante falaciosa. É atribuída à educação, principalmente pelo ideário posto pelas propostas de reformas educacionais, a função social de promover, entre outras "boas ações", o desenvolvimento ecologicamente sustentável; a inserção no mercado de trabalho pela porta da empregabilidade e do empreendedorismo; a segurança e a paz mundial, além da redução e alívio da miséria. Por esse prisma reificante, a educação vem assumindo na sociedade capitalista, sobretudo no momento histórico da atual crise do capital (Mészáros, 2005), o papel de fomentar soluções e ações perante os conflitos postos pela contradição fundamental entre capital e trabalho.

Em outras palavras, o que temos à nossa frente é um projeto educativo voltado, prioritariamente, para atender às necessidades do capital em seu processo de expansão e acumulação ampliada em um momento particularmente crítico para o sistema capitalista. A esse respeito, Rabelo, Jimenez e Mendes Segundo (2015) postulam que nas sociedades de classes, como não poderia deixar de ser, a educação é chamada a ajustar os indivíduos aos ditames do trabalho explorado, desconsiderando a formação de homens livres e plenos. Nesse sentido, os projetos educacionais a serviço da reprodução do capital acabam efetivando-se pela negação do conhecimento capaz de revelar as determinações do real e da complexidade e multiplicidade de suas dimensões, pondo-se a serviço da manipulação ideológica das consciências com o objetivo de naturalizar a lógica da exploração e da desumanização que se aprofundam exponencialmente na sociedade atual.

No entanto, recorrendo ao pensamento dialético e historicamente situado, compreendemos que, em face desse agravamento da problemática educacional, em que crises justificam reformas (Romanelli, 1996), não podemos desconsiderar que, embora sua função social permeie todo o desenvolvimento histórico dos homens, complexificando-se juntamente com estes, a educação possui particularidades atinentes às necessidades postas em cada momento histórico da sociabilidade humana.

As reformas educacionais nos países do dito terceiro mundo, a exemplo do Brasil, caracterizaram-se pela promoção e acomodação às novas configurações da divisão internacional do trabalho e da riqueza, cuja base é a redução do sistema educacional ao ensino elementar e reprodutivista. Assim, com uma conotação política e ideológica bastante definida, as reformas são "dirigidas a uma categoria importantíssima em termos políticos: os excluídos, agora redefinidos como pobres" (Leher, 1998, p. 186).

Para tanto, faz-se fundamental o papel do Estado na implantação de estratégias reformistas. Recuperando a concepção de Estado em Marx, compreendemos que, em sua obra, especialmente em O capital, encontra-se "a chave" para a compreensão dos fundamentos do Estado burguês. Assim sendo, entendemos que é nessa direção que se pode pensar em uma forma de superar essa sociabilidade. Para tanto, faz-se necessário conhecê-la, desvelando a função do Estado na organização e no monitoramento do modo de produção capitalista na atualidade, visto que a 
contemporaneidade contempla dimensões de atuação do Estado que ainda não estavam plenamente desenvolvidas à época de Marx. Nesse sentido, consideraremos também a análise de diversos estudiosos do campo marxista que, com sua contribuição inaugural, procuraram desvendar o papel do Estado na sociedade burguesa e seus desdobramentos na contemporaneidade.

Gorende (2013, p. 31), importante historiador marxista brasileiro, em uma contextualizada apresentação ao livro O capital, recupera a "intenção de Marx de escrever um livro somente sobre o Estado capitalista". Tal projeto não se configurou, mas é possível visualizar esse propósito, in nuce, ao longo do Livro 1 da obra de Marx. Como nos lembra o historiador, não é o estado que cria a sociedade civil, mas é a sociedade civil que produz o Estado. Nessa mesma edição, o texto intitulado "Considerações sobre o método", de Giannotti (2013, p. 87), traduz o pensamento de Marx ao afirmar que "o Estado sempre esteve presente no desenvolvimento capitalista, mas o mercado, principalmente na sua fase adulta, recusa essa interferência acreditando ser mais eficaz do que qualquer intervenção pública".

Parece que o mercado, ao se declarar como instância independente do Estado, busca paradoxalmente confirmar a tese de Marx, mas como se ele próprio, o mercado, contivesse o todo da sociedade civil. De fato, se a sociedade civil se torna visível no auge do desenvolvimento do capitalismo, em que há uma separação mais nítida entre as funções do Estado e da sociedade não estatal, tal fato apenas demonstra que é o povo que produz o Estado, e não o inverso, mas isso não quer dizer que é o mercado que produz o Estado ou dele prescinde. Eis a tese liberal e seus exageros neoliberais: libertem o mercado do Estado!

Em uma perspectiva oposta ao projeto neoliberal, intenta-se, ao contrário, submeter o mercado ao Estado democrático. Como destaca Tonet (2016), apregoa-se aqui a tomada do Estado para que seja possível humanizar o capital e propiciar uma sociedade mais justa e igualitária sob a égide do mercado. Essa tomada do Estado permitiria despir o capital de suas características mais "selvagens" e impor-lhe determinados limites. Ao mesmo tempo, ocorreria a democratização do Estado em várias instâncias sociais, na realização de políticas sociais mais universalizadas, amparados pela formação de cidadãos conscientes, críticos e participativos.

Como evidencia, contudo, o referido autor, essa lógica não se adéqua ao modo de produção capitalista, que tem como cerne a exploração do trabalho de uma classe. Trata-se, na verdade, de sua vestimenta ideológica, pois "o Estado moderno foi configurado para dar suporte à autoacumulação do capital” Tonet (2016, p. 3). Busca-se, portanto, "trilhar o caminho das reformas, e não de perseguir utopias (a revolução, o socialismo)".

Marx (2013, p. 433), em sua crítica ao grau de exploração da força de trabalho, em que desvela os limites da jornada de trabalho, destaca exatamente o papel central do Estado no processo de exploração do trabalhador:

É natural, assim, que o prolongamento da jornada de trabalho, que o capital, desde o século XIV até o fim do século XVII, procurou impor aos trabalhadores adultos por meio da coerção estatal, coincida aproximadamente com a limitação do tempo de trabalho que, na segunda metade do século XIX, foi imposta aqui e ali pelo Estado para impedir a transformação do sangue das crianças em capital. 
Mesmo a redução da jornada de trabalho, segundo Marx (2013, p. 592), decorre da crescente revolta da classe operária que "obrigou o Estado a reduzir à força o tempo de trabalho e a impor à fábrica propriamente dita uma jornada normal de trabalho". Todavia, o capital, impedido legalmente de prolongar ainda mais a jornada de trabalho e buscando manter a produção crescente de mais valor, "lançou-se com todo seu poder e plena consciência à produção de mais-valor relativo por meio do desenvolvimento acelerado do sistema da maquinaria" (Marx, 2013, p. 592). Dito de outro modo, o capital aplica o método de produção de mais-valor relativo que faz com que, com o aumento da força produtiva do trabalho, o trabalhador "seja capaz de produzir mais com o mesmo dispêndio de trabalho no mesmo tempo", estratégia que fica imune à regulação do Estado.

Aproximando-nos da crítica ao Estado burguês no contexto de crise atual, pressuposto essencial para compreendermos os elementos basilares dos princípios do processo reformista reiterado hodiernamente pelos capitalistas, Antunes (2011, p. 14), na trilha de Mészáros (2011) e sua tese sobre a crise estrutural do capital, assinala que, levando-se em conta

[...] a inseparabilidade das três dimensões do sistema do capital, que são completamente articulados - capital, trabalho e Estado -, é inconcebível emancipar o trabalho sem simultaneamente superar o capital e também o Estado. Isso porque, paradoxalmente, o material fundamental que sustenta o pilar do capital não é o Estado, mas o trabalho, em sua contínua dependência estrutural do capital [...]. Enquanto as funções controladoras vitais do sociometabolismo não forem efetivamente tomadas e autonomamente exercidas pelos produtores associados, mas permanecerem sob a autoridade de um controle pessoal separado (isto é, o novo tipo de personificação do capital), o trabalho enquanto tal continuará reproduzindo o poder do capital sobre si próprio, mantendo e ampliando materialmente a regência da riqueza alienada sobre a sociedade.

O atual contexto da sociabilidade é ainda mais perturbador se a tese de Mészáros (2011), exposta em sua obra Para além do capital, estiver correta: segundo o autor, a sociabilidade do capital atravessa hoje não apenas uma crise cíclica, mas uma crise de natureza estrutural. Para advogar sua tese, ele destaca a ativação das tendências destrutivas do capital, a exemplo do investimento maciço do capital no complexo industrial militar e na produção descartável e do desperdício. Essa destruição das forças produtivas é, paradoxalmente, promovida pelo próprio Estado associado ao capital, na busca de reverter a queda tendencial das taxas de lucros, no contexto da crise vigente.

Na perspectiva do pensador húngaro, o Estado capitalista promove a fusão mística entre o produtor, o comprador, o consumidor e o Estado - este último um cofre abundante e aparentemente inesgotável, já que o Estado não pode falir. Tal estratégia permitirá, para ele, a legitimação ideológico-política e a autorreprodução ampliada do capital no atual contexto. Nessa direção, o capital busca inovar os meios 
de produção, deslocando-a para a produção bélica, bem mais lucrativa e que não precisa se deter aos constrangimentos das necessidades humanas. É exatamente nessa conjuntura que as inovações científicas e produtivas se voltam exclusivamente aos interesses privados dominantes, mediados pelo Estado capitalista, que por sua vez manipula a opinião pública em um controle combinando com os meios de comunicação de massa.

Desse modo, o capitalismo, no quadro da crise atual, impõe diversas estratégias para evitar pôr em risco sua supremacia monopolista. Assim sendo, a saída da reestruturação da realidade mediante reformas esporádicas, que não mudam significativamente a divisão do trabalho e da riqueza, como atesta a visão política da social-democracia e sua natureza reformista, busca garantir a governabilidade e a sustentabilidade econômica do mundo capitalista.

Em sua balizada crítica à chamada democracia moderna, imposta pelo capital, no contexto de crise, Toledo (1993, p. 36) questiona a proclamada possibilidade de democratização no interior das instituições estatais e da sociedade civil, amparados na crença na possibilidade de uma democracia de caráter popular em plena ordem capitalista. Assim lança as seguintes perguntas:

[...] as classes proprietárias admitirão - sem apelar para o poder repressivo do Estado - as reformas profundas e as transformações sociais na direção de uma democracia sob hegemonia popular? Admitirão os capitalistas, um dia, submeterem-se às decisões democráticas dos trabalhadores dentro de suas fábricas? No plano das estruturas políticas, é possível conceber a universalização do princípio de elegibilidade a todos os níveis do Estado burguês - eleição dos magistrados, da burocracia civil, dos oficiais das Forças Armadas?

Nessa direção, Toledo (1993, p. 9) afirma ainda que, se os regimes democráticos vêm permitindo algumas conquistas sociais e políticas para as massas populares, a sua organização idealizada tem profundo efeito mistificador e contrarrevolucionário.

Por fim, Toledo (1993, p. 12) assegura a necessidade da crítica classista ao caráter substantivamente não democrático da sociedade burguesa e denuncia duramente o projeto de "conversão democrática", que vem corrompendo a esquerda no Brasil. Nas palavras do autor, com efeito, para a dita esquerda democrática, "ontem como hoje, aos socialistas nada mais restaria que lutar pela defesa da democracia o nome da (única) revolução possível de nossos tempos". Para nós, afinados com o projeto que interessa à classe trabalhadora, resta a tarefa de continuarmos a radical denúncia quanto aos efeitos desumanos do sistema do capital sobre o conjunto da humanidade e do planeta e articularmos essa denúncia à afirmação da possibilidade histórica da revolução socialista.

Para finalizarmos, é importante relembrar que Marx, ao tratar da temática da educação, elaborou um conjunto de formulações e denúncias acerca do ensino burguês destinado à classe trabalhadora. Tais denúncias, combinadas a sua crítica radical à economia política burguesa, contempla a defesa de uma educação 
pública gratuita para todas as crianças, vinculada à abolição do trabalho infantil nas fábricas. É válido destacar que a defesa desse ponto acompanhará Marx até O capital. Para tanto, adverte o autor, há necessidade de superar-se a divisão de trabalho mediante um processo revolucionário na contramão da forma capitalista de produção, em que o trabalho está subjugado à lógica de expansão ampliada do capital.

Ora, se a leitura da perspectiva política e econômica do liberalismo já comporta uma crítica aos limites do reformismo nos termos de Bobbio (2000), tal negação ainda é mais radical na leitura marxista, visto que procura ir à própria raiz do que está em jogo nos processos de mudança social. Não se trata de uma mera negação das possibilidades levantadas pelas estratégias legalista, gradualista, focalista e parcialista da atuação do Estado burguês no atual momento de nossa sociabilidade. Não traduz, portanto, uma crítica por si mesma. A estratégia legalista poderia servir também aos interesses da classe trabalhadora, na medida em que pode também consumar na legislação pontos de interesses dessa classe, como forma de o legislador viabilizar na opinião pública a racionalidade reformista. Nesses termos, como o legal visa ao legítimo, implicará sempre estratégias de convencimento ou de resistência dos sujeitos envolvidos, portanto em suas possibilidades e limites de efetiva realização.

É certo que a luta social nos termos do Estado de direito burguês será, em última instância, inglória para o trabalhador, visto que o direito legal e sua especificidade emergem da luta de classes e de sua crescente complexificação, mas na sociabilidade atual seu protagonismo cabe, evidentemente, aos representantes do capital e de sua ideologia. A prova visível de tal realidade se presentifica na contemporaneidade, uma vez que se verifica a judicialização da política, que vem legalizando e justiçando diversas arbitrariedades e abusos do Estado em nome do suposto Estado de direito, que é, na verdade, a legalização do direito de propriedade. Ora, a preservação do bem comum é, no fundo, a preservação de quem tem bens, já que o trabalhador não tem bens a serem protegidos pelo Estado.

Em teoria, não há problemas, em si, com políticas sociais gradualistas, embora as transformações sociais sejam pouco tributárias de mudanças evolutivas, regulares e lineares da realidade social. Mudanças e transformações sociais, invariavelmente, ocorrem ao longo do tempo, mas o motivo porque ocorrem, seu ritmo e direção são complexos e difíceis de prever, especialmente quando se tratam de fatos e relações humanas. Pensá-las como ordenadas e progressivas nada mais é que a configuração da visão ideológica, positivista e parcialista de mundo, visto que o positivo não pode resultar da mera negação do supostamente negativo, desordenado e irracional, pois tal pressuposto não confere com o complexo de complexos que constitui o real. Mas é fato que a realidade pode ser torturada em nome da ideologia.

Já o uso do focalismo e a adoção de medidas parciais merecem uma discussão à parte. Para o marxismo, a categoria da totalidade não comporta qualquer pretensão totalitária. Analisar o movimento do real, dividindo o todo em partes e focando nas especificidades de certas produções da realidade é, obviamente, prática científica 
legítima e pública consagrada, mas esta precisa ter como fundamento a categoria do todo, sem o que as análises podem cair em uma leitura enviesada da realidade, porque desprovidas do entendimento das mediações que entrelaçam cada objeto à esfera prioritária da totalidade que lhe atribui sentido. Obviamente, a focalização, enquanto análise e intervenção em um fenômeno social, pode servir a interesses bem variados, até mesmo quanto aos diversos fins e usos da ciência.

A questão central emerge quando tais políticas focais e parciais são colocadas e racionalizas como a condição possível para lidar com as urgências da realidade social. Às vezes propostas como temporárias ou como passo inicial para mudanças futuras, costumeiramente se tornam o temporário que veio para ficar, ou a legalização do provisório como estratégia de combate a mudanças efetivas e significativas. Ora, não se trata de criticar o modus operandi do Estado burguês por si mesmo, mas desvelar os próprios limites das políticas reformistas e liberais, que, a rigor, expressam uma contradição lógica, pois, é oportuno reiterarmos, no fundo cuidam de mudar para que tudo permaneça essencialmente o mesmo.

\section{CONSIDERAÇÕES FINAIS}

Em linhas gerais, compreendemos que a educação é capaz de mediar, no contexto das contradições próprias do sistema do capital em crise, atividades que podem apontar, eventualmente, para a direção de superação do capital, na forma de "atividades educativas emancipadoras", conforme formulação original de Tonet (2005). No entanto, tal possibilidade tende a ser residual e pouco relevante fora de uma luta de classe acirrada e efetiva.

Entendemos que as reformas educacionais impostas à educação brasileira, ilustrada, por exemplo, pela reforma do ensino médio iniciada no final dos anos de 1990, atendem, em larga medida, muito mais às recomendações dos organismos internacionais em sintonia com o projeto neoliberal do grande capital em crise do que aos interesses do país e da maioria da população que vive dos rendimentos do trabalho. São mudanças, mas que pouco dizem a respeito da verdadeira estrutura econômica e social que marca a desigual sociedade brasileira. A reforma e suas estratégias de implantação possuem limites tão visíveis que são objeto de crítica até mesmo da leitura liberal e burguesa de economia.

A crítica marxista não se resume a fazer a crítica pela crítica e muito menos por abdicar de soluções alternativas. Tais soluções não se consagram por si mesmas, pois não se trata de uma questão meramente eficientista e operacional. As mudanças necessárias precisam levar em conta os fundamentos sobre os quais se estrutura a atual organização da nossa sociabilidade, uma vez que as posições políticas sobre tal realidade são obviamente multifacetadas. Há, no campo teórico e político, diversas alternativas ao reformismo, mas que são rechaçadas de pronto pela ideologia burguesa por serem supostamente infectadas por um vício de origem: são parciais, dispersas, ilegais, disruptoras. Nada mais que um espelho das próprias reformas que propõem. 
É óbvio que, no contexto da atual crise do capital, o reformismo se torne a própria resposta lógica à crise. Mas o problema pode ser mais profundo. Pode responder, na realidade, à queda tendencial das taxas de lucros que vem comprometendo a governabilidade e a sustentabilidade da ordem do capital em crise, como alertou Marx. Investir na educação cumpre nessa lógica um duplo papel: investir "prioritariamente" na educação responde ideologicamente à tese de que esse é o caminho para superar as diferenças econômicas e sociais de um país como o Brasil; trata-se da reforma possível que na prática muda para não mudar, pois a educação que nos cabe corresponde à posição que ocupamos na divisão internacional e capitalista de trabalho.

\section{REFERÊNCIAS}

AGUIAR, R. R. A Reforma Educacional Brasileira (1995-2000): da transição a um modelo singular da gestão. 2003. Tese. (Doutorado em Educação) - Faculdade de Educação, Universidade Federal do Ceará, Fortaleza, 2003.

ANTUNES, R. Os sentidos do trabalho: ensaio sobre a afirmação e a negação do trabalho. São Paulo: Boitempo, 2011.

BID - Banco Interamericano de Desenvolvimento. Latin America after a decade of reforms economic and social process - 1997 - Report. Washington, DC: BID, 1997.

BOBBIO, N. Teoria geral da política: a filosofia política e as lições dos clássicos. Rio de Janeiro: Campus, 2000.

BRESSER-PEREIRA, L. C. Bobbio defende o "compromisso" entre o liberalismo e o socialismo. Folha de S. Paulo, São Paulo, 5 dez. 1994. Caderno Mais!

BUENO, R. A centralidade do argumento neoliberal em Von Mises, Hayek e Friedman: uma via para a crítica política contemporânea. Ciências Sociais Aplicada em Revista, Marechal Cândido Rondon, v. 12, n. 23, p. 9-34, jul./dez. 2012. N

COMTE, A. Discurso sobre o espírito positivo: ordem e progresso. Porto Alegre: Globo, 1976.

FERREIRA, E. B.; FONSECA, M. O planejamento das políticas educativas no Brasil e seus desafios atuais. Perspectiva, Florianópolis, v. 29, n. 1, p. 69-96, jan./ jun. 2011. https://doi.org/10.5007/2175-795X.2011v29n1p69

FONSECA, M. O Banco Mundial como referência para a justiça social no terceiro mundo: evidências do caso brasileiro. Revista da Faculdade de Educação, São Paulo, v. 24, n. 1, p. 37-69, jan./jun. 1998. http://dx.doi.org/10.1590/S010225551998000100004

GIANNOTTI, J. A. Considerações sobre o método. In: MARX, K. O capital. Livro I: O processo de produção do capital. Tradução Rubens Enderle. São Paulo: Boitempo, 2013.

GORENDE, J. Apresentação. In: MARX, K. O capital. Livro I: O processo de produção do capital. Tradução Rubens Enderle. São Paulo: Boitempo, 2013. 
LEHER, R. Da ideologia do desenvolvimento à ideologia da globalização: a educação como estratégia do Banco Mundial para "Alivio" da pobreza. 1998. Tese (Doutorado em Educação) - Faculdade de Educação da Universidade de São Paulo, São Paulo, 1998.

LEWIN, K. The conflict between Aristotelian and Galileian modes of thought in contemporary psychology. In: GOLD, M. (ed.). The complete social scientist: a Kurt Lewin reader. Washington, DC: APA, 1999. p. 37-66.

MAIA FILHO, O. N. A reforma do ensino médio: da pedagogia das competências à gestão tecnocrática em educação. 2004. Tese (Doutorado) - Programa de PósGraduação em Educação Brasileira, Universidade Federal do Ceará, Fortaleza, 2004. MAIA FILHO, O. N.; JIMENEZ, S. A chave do saber: um exame crítico do novo paradigma educacional concebido pela ONU. In:JIMENEZ, S. V.; RABELO,J. (org.). Trabalho, educação e luta de classes. Fortaleza: Brasil Tropical, 2004. p. 107-124.

MANCEBO, D. Educação superior no Brasil: expansão e tendências (1995-2014). In: Reunião Nacional da Associação Nacional de Pós-Graduação e Pesquisa em Educação, 37., 2015, Florianópolis. Anais eletrônicos [...]. Florianópolis: ANPEd; UFSC, 4-8 out. 2015. Disponível em: http://www.anped.org.br/biblioteca/item/ educacao-superior-no-brasil-expansao-e-tendencias-1995-2014. Acesso em: 27 fev. 2018.

MARX, K. Elementos fundamentales para la crítica de la economía política (Gundrisse) 1857-1859. Ciudad de México: Siglo Veintiuno, 1989.

MARX, K. O capital: crítica da economia política. São Paulo: Boitempo Editorial, 2013. Livro 1.

MENDES SEGUNDO, M. D. O Banco Mundial e suas implicações na política de financiamento da educação básica do Brasil: o FUNDEF no centro do debate. 2005. 230f. Tese (Doutorado) - Programa de Pós-Graduação em Educação Brasileira, Universidade Federal do Ceará, Fortaleza, 2005.

MÉSZÁROS, I.A educação para além do capital. São Paulo: Boitempo Editorial, 2005. MÉSZÁROS, I. A crise estrutural do capital. Tradução Raul Cornejo et at. São Paulo: Boitempo, 2011.

RABELO, J.; JIMENEZ, S.; MENDES SEGUNDO, M. D. (org.). O movimento de educação para todos e a crítica marxista. Fortaleza: Imprensa Universitária, 2015. Disponível em: http://www.repositorio.ufc.br/bitstream/riufc/16670/1/2015_ liv_jrabelo.pdf. Acesso em: 16 ago. 2016.

ROMANELLI, O. O. História da educação no Brasil. 18. ed. Petrópolis: Vozes, 1996. TOLEDO, C. N. A modernidade democrática da esquerda: adeus à revolução? Campinas: IFCH/UNICAMP, 1993. Disponível em: https://www.ifch.unicamp.br/ criticamarxista/arquivos_biblioteca/artigo285CM_1.3.pdf.Acesso em: 15 jan. 2018. TONET, I. Educação, cidadania e emancipação humana. Ijuí: Editora Unijuí, 2005. TONET, I. Entre reforma e revolução. [Campinas: s.n.]: 2016. Disponível em: http://ivotonet.xp3.biz/arquivos/Entre_reforma_e_revolucao.pdf. Acesso em: 15 jan. 2018. 


\section{SOBRE OS AUTORES}

Osterne Nonato Maia Filho é doutor em educação pela Universidade Federal do Ceará (UFC). Professor da Universidade Estadual do Ceará (UECE). E-mail: osterne_filho@uol.com.br

Maria das Dores Mendes Segundo é doutora em educação brasileira pela Universidade Federal do Ceará (UFC). Professora da Universidade Estadual do Ceará (UECE).

E-mail: mariadores.segundo@uece.br

Josefa Jackline Rabelo é doutora em educação pela Universidade Federal do Ceará (UFC). Professora da mesma instituição.

E-mail: jacklinerabelo@uol.com.br

Maria Susana Vasconcelos Jimenez é doutora em educação pela Alliant International University (Estados Unidos). Professora da Universidade Federal do Ceará (UFC).

E-mail:susana_jimenez@uol.com.br

Recebido em 13 de abril de 2018

Aprovado em 04 de junho de 2018 